\title{
Innovative technology shows impact of glycaemic control on peripheral retinal vessels in adolescents with type 1 diabetes
}

\author{
Valli Velayutham $^{1}$ • Paul Z. Benitez-Aguirre ${ }^{1,2}$ - Maria E. Craig ${ }^{1,2,3} \cdot$ Gerald Liew $^{1,2}$. \\ Tien Y. Wong ${ }^{4,5}$ - Alicia J. Jenkins ${ }^{5}$ - Kim C. Donaghue ${ }^{1,5}$
}

Received: 14 February 2017 / Accepted: 1 June 2017 /Published online: 15 July 2017

(C) Springer-Verlag GmbH Germany 2017

\begin{abstract}
Aims/hypothesis Retinal imaging enables non-invasive microvasculature assessment; however, only central retinal vessels have been studied in type 1 diabetes. Peripheral smaller vessels have a major haemodynamic role and may differ from central vessels in their response to the diabetic milieu. We hypothesise that diabetes has a greater impact on peripheral retinal vessels vs central vessels.

Methods Retinal photographs from adolescents $(n=736$; age 12-20 years) with type 1 diabetes were graded (Singapore I Vessel Assessment) with vessel calibres measured in the 'central zone' as central retinal arteriolar and venular equivalents (CRAE and CRVE, respectively) and the 'extended zone' as mean width of arterioles and venules (MWa and MWv, respectively). Multivariable linear regression was used to explore associations between vessel calibres and $\mathrm{HbA}_{1 \mathrm{c}}$, diabetes duration, sex and $\mathrm{BP}$. Results Mean $\pm \mathrm{SD}$ age was $14.1 \pm 1.5$ years, $\mathrm{HbA}_{1 \mathrm{c}}$ was $8.5 \pm 1.3 \%(69.4 \pm 14.1 \mathrm{mmol} / \mathrm{mol})$ and median diabetes duration was 4.9 years (interquartile range 3.1-7.6 years). Wider MWa was associated with $\mathrm{HbA}_{1 \mathrm{c}}(\beta 0.01$ [95\% CI 0.004,
\end{abstract}

Valli Velayutham and Paul Z. Benitez-Aguirre are equal first authors.

Kim C. Donaghue

kim.donaghue@health.nsw.gov.au

1 The Children's Hospital at Westmead, 212 Hawkesbury Road, Westmead, NSW 2145, Australia

2 Westmead Clinical School, University of Sydney, Sydney, NSW, Australia

3 School of Paediatrics, University of New South Wales, Sydney, NSW, Australia

4 Department of Ophthalmology, University of Melbourne and Centre for Eye Research, East Melbourne, VIC, Australia

5 Singapore Eye Research Institute, Singapore, Republic of Singapore
$0.03])$, longer diabetes duration $(0.07[0.02,0.13])$ and higher systolic BP $(0.04[0.02,0.05])$. MWv was associated with $\mathrm{HbA}_{1 \mathrm{c}}(0.02[0.009,0.03])$ and higher systolic BP $(0.04[0.03$, $0.06])$. CRAE was associated with longer diabetes duration ( 0.93 $[0.58,1.28])$ and higher systolic BP $(-0.28[-0.37,-0.19])$. CRVE was associated with longer diabetes duration $(0.91$ $[0.42,1.41])$ and higher systolic BP $(-0.20[-0.33,-0.07])$. Girls had wider vessels (for all four calibre measurements). Conclusions/interpretation In adolescents with type 1 diabetes, higher $\mathrm{HbA}_{1 \mathrm{c}}$ is associated with adverse changes to peripheral smaller retinal vessels but not central vessels. The predictive value of retinal vascular imaging should be evaluated using longitudinal data.

Keywords Adolescents · BP · Diabetes complications · Diabetic retinopathy $\cdot$ Glycaemic control $\cdot$ Retinal vascular calibre · Singapore I vessel assessment · Type 1 diabetes

$\begin{array}{ll}\text { Abbreviations } \\ \text { CRAE } & \text { Central retinal arteriolar equivalent } \\ \text { CRVE } & \text { Central retinal venular equivalent } \\ \text { DBP } & \text { Diastolic BP } \\ \text { MWa } & \text { Mean width of arterioles } \\ \text { MWv } & \text { Mean width of venules } \\ \text { SBP } & \text { Systolic BP }\end{array}$

\section{Introduction}

Retinal microvasculature offers a unique opportunity to better understand the pathophysiology of diabetes complications. Adolescence and puberty are high-risk periods for the development of vascular complications [1]; however, adolescence is a difficult age to monitor for complications. The retinal 
vasculature is accessible to non-invasive visualisation, offering the opportunity to better understand early microvascular pathophysiology. Retinal microvasculature changes may reflect early retinal and systemic vascular dysfunction, and predict later micro- and macrovascular disease including retinopathy, increased cardiovascular morbidity/mortality rates and nephropathy [2-10]. The relationship between retinal vascular changes and diabetes complications has already been demonstrated, but published studies so far have only focused on central retinal vessels within one disc diameter from the optic disc.

Capillary vasodilatation is the earliest sign of diabetic retinopathy $[11,12]$. Retinal vasodilatation and hyperperfusion are postulated as key initiating factors in the development of diabetic retinopathy $[13,14]$. Experimental studies have shown that increased retinal blood flow and vasodilation reflect underlying autoregulatory dysfunction [15]. This could be due to hyperglycaemia-mediated endothelial dysfunction, retinal hypoxia from retinal capillary non-perfusion [15], upregulation of inflammatory mediators [16], superoxide formation $[13,14]$ and downregulation of calcium-activated potassium channels [17]. In diabetes, wider retinal venules may predict subsequent retinopathy, but the effect on arterioles is more difficult to discern because of the opposing effects of high BP and increasing age during adolescence [18]. Other factors that may influence retinal vessel calibre include atherosclerosis, age-related macular degeneration, kidney disease and use of vasoactive medications, such as calcium channel blockers, which is uncommon in adolescents. Nevertheless, the diabetic milieu may demonstrate different effects on the retinal blood vessels in adolescents compared with adults.

With innovative technology, it is now possible to measure the smaller peripheral vessels in the retina, two optic disc diameters away from the optic disc margin. Smaller peripheral vessels host endothelial cells and pericytes, both of which play a major role in the pathogenesis of microvascular complications. Pericytes are vascular smooth muscle cells present in smaller vessels including capillaries, precapillary arterioles and in the venous end of capillaries. Pericytes are damaged early in diabetes [19]. Studying these smaller peripheral vessels, which are one-tenth of the size of central vessels, may provide better understanding of the future risk of complications than central vessel analysis.

We hypothesise that in adolescents with type 1 diabetes hyperglycaemia is associated with wider vessel calibres at the periphery of the retina, especially early in the course of disease. We further hypothesise that this relationship remains after adjustment for other factors known to influence vessel calibre including BP and diabetes duration.

\section{Methods}

Study population The study population comprised adolescents with type 1 diabetes who were prospectively assessed for diabetes complications at The Children's Hospital at Westmead in Sydney, Australia, between 1990 and 2007. Inclusion criteria were age 12-20 years, type 1 diabetes duration of at least 2 years, gradable retinal photographs suitable for retinal vascular geometry grading and absence of retinopathy (defined as no microaneurysm/haemorrhage).

The ethics committee of the Sydney Children's Hospitals Network approved the study and written informed consent was obtained from parents of all participants.

Complications assessment Participants were assessed by standardised interviews, clinical examinations and laboratory investigations during the visit as previously described [20]. Briefly, height and weight were measured to estimate BMI $\left(\mathrm{kg} / \mathrm{m}^{2}\right)$ and SD scores were determined using the Center for Disease Control population-based data. BP was measured with a sphygmomanometer using an appropriately sized cuff in seated individuals after $5 \mathrm{~min}$ rest. Venous blood samples were obtained for measurement of total cholesterol levels and glycaemic control, which was assessed by glycated haemoglobin calorimetrically before February 1994 and subsequently by $\mathrm{HbA}_{1 \mathrm{c}}$ with HPLC (Diamat Bio-Rad analyser, Bio-Rad, Herculus, CA, USA). Glycated haemoglobin values were converted to $\mathrm{HbA}_{1 \mathrm{c}}$ $($ Diamat $=1.9088+0.0043 \times \mathrm{GHb} ; r=0.92)$. The interassay coefficients of variation were $1.1 \%$ and $1.2 \%$ for values of $\mathrm{HbA}_{1 \mathrm{c}}$ of $5.95 \%$ and $9.76 \%$, respectively.

Retinal photography Mydriatic seven-field stereoscopic fundal photographs were taken using a TRC 50-VT Topcon Fundus Camera (Tokyo Optical, Tokyo, Japan) to assess for retinopathy. Images were taken initially with film and from September 2004 with digital photography [1]. Camera settings, including the angle of retinal photography, remained unchanged. All film slides before September 2004 were digitised using a CanoScan FS2710 (Canon, Tokyo, Japan) film scanner, set to automatic exposure and focus, with 24 bit colour and a maximum resolution of 2720 dpi without enhancement. These digitised images were used to assess retinal vascular geometry.

Retinal vessel measurements Retinal vessel calibres were analysed from retinal photographs of the central field. All slides were individually assessed for grading suitability. Images were considered unsuitable for grading if they were blurred, did not completely represent all zones or if there were fewer than four large arterioles or venules gradable in one image. Of the images, $215(22 \%)$ were either unsuitable for grading $(n=47)$ and/or showed retinopathy $(n=168)$. Therefore, 736 images were gradable. Individuals who were excluded did not differ significantly in age, sex, diabetes duration, retinopathy status, cholesterol level and BP from those included.

Right eye digitised retinal photographs were analysed by a single trained grader, masked to participants' characteristics, using a semi-automated computer-assisted image program 
(Singapore I Vessel Assessment, National University of Singapore, Republic of Singapore) (Fig. 1). The grader allowed the software to detect the centre of the optic disc and divided the region into three subzones (A, B and C) surrounding the optic disc, each zone corresponding to $0.5,1.0$ and 2.0 optic disc diameters away from the optic disc margin, respectively. Zone $\mathrm{C}$ includes zones $\mathrm{A}$ and $\mathrm{B}$ (Fig. 1). Once the optic disc and the three concentric subzones were located, the grader executed the program to trace all vessels. The vessels were then identified and labelled as arterioles or venules and the width of the vessels measured.

Retinal vascular outcome measures The mean widths of the six large arterioles and venules in central zone B are represented by the central retinal arteriolar equivalent (CRAE) and the central retinal venular equivalent (CRVE), respectively. CRAE and CRVE were calculated by iteratively joining the consecutive pairs of vessel mean widths using a formula described by Knudtson et al [21]. The mean widths of the peripheral vessels are represented by the mean widths of arterioles and venules (MWa and MWv, respectively) in extended zone C. MWa and MWv are a recursive combination of the root segment and its descendants. This was obtained by the average combined width of the parent and daughter segments of a vessel (Fig. 1). A high degree of reliability was found between the different retinal vessel calibre measurements used. Based on duplicate assessment of 72 images by two independent graders, the intraclass correlation coefficients were: 0.919 for CRAE, 0.679 for CRVE, 0.913 for MWa and 0.944 for MWv in extended zone C, and 0.908 for CRAE, 0.745 for CRVE, 0.88 for MWa and 0.84 for MWV in central zone B.

Statistical analysis Descriptive statistics are reported as mean $\pm \mathrm{SD}$ for parametric data or median (interquartile range [IQR]) for skewed data. Participants were stratified into

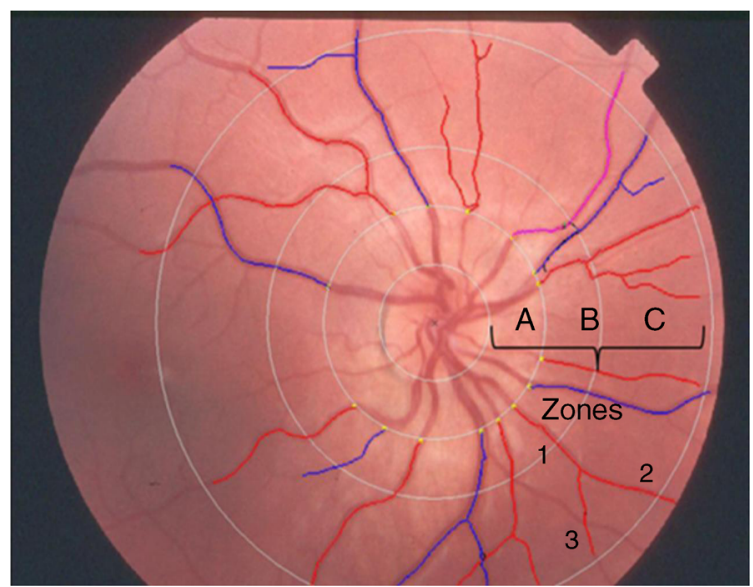

Fig. 1 Digitised retinal photograph indicating retinal zones A, B and C $(0.5,1.0$ and 2.0 optic disc diameters from the optic disc, respectively). 1 , root segment; 2 and 3, daughter segments. Image courtesy of P.Z. Benitez-Aguirre tertiles for $\mathrm{HbA}_{1 \mathrm{c}}(<7.8 \%, 7.9-8.9 \%$ and $>9 \%[<61.7 \mathrm{mmol} /$ $\mathrm{mol}, 62.8-73.8 \mathrm{mmol} / \mathrm{mol}$ and $74.8-144.8 \mathrm{mmol} / \mathrm{mol}]$ ) for analysis. Differences in continuous variables were compared across the three $\mathrm{HbA}_{1 \mathrm{c}}$ groups using ANOVA with the Tukey test for post hoc analysis. The major outcome measures were retinal vascular calibres in the central zone (CRAE, CRVE) and extended zone (MWa, MWv). Multivariable linear regression was used to analyse the associations between the four outcome measures and explanatory variables $\left(\mathrm{HbA}_{1 \mathrm{c}}, \mathrm{BMI}\right.$ and cholesterol). Two multivariable models were constructed to avoid inclusion of collinear variables in the same model. Model 1 included $\mathrm{HbA}_{1 \mathrm{c}}$, type 1 diabetes duration, sex, height and systolic $\mathrm{BP}$ (SBP). Model 2 included $\mathrm{HbA}_{1 \mathrm{c}}$, type 1 diabetes duration, sex, height and diastolic BP (DBP). Data are expressed as regression coefficients $(\beta[95 \% \mathrm{CI}])$ and $p<0.05$ was considered to be significant. Analyses were performed using SPSS v.22 (IBM, Armonk, NY, USA).

\section{Results}

Of the 951 adolescents who had retinal photographs taken over the study period, $736(77 \%)$ were free of retinopathy and had photographs suitable for retinal geometry grading. The study population had a mean age of $14.1 \pm 1.5$ years, a median diabetes duration of $4.9(3.1-7.6)$ years and a mean $\mathrm{HbA}_{1 \mathrm{c}} 8.5 \pm 1.3 \%(69.4 \pm 14.1 \mathrm{mmol} / \mathrm{mol})$. The characteristics of participants stratified by $\mathrm{HbA}_{1 \mathrm{c}}$ tertile are shown in Table 1. None of the participants were hypertensive (defined as SBP and DBP $\geq 95$ th centile for sex, age and height) [22]. Across the three $\mathrm{HbA}_{1 \mathrm{c}}$ tertiles, MWa and $\mathrm{MWv}$ increased; this relationship was not observed for CRAE or CRVE (Table 1, Fig. 2). $\mathrm{HbA}_{1 \mathrm{c}}$ as a continuous variable was associated with wider vessel calibres in the extended zone (MWa, MWv) but not in the central zone (Table 2).

Wider vessel calibre (MWa and MWv) in the extended zone was associated with higher SBP and DBP in multivariable analyses. Conversely, central zone vessel calibres (CRAE and CRVE) were narrower with higher BP (Table 2). Wider vessel calibres in both zones (CRAE, CRVE, MWa and MWv) were associated with longer diabetes duration (Table 2).

The association between peripheral vessel calibre and $\mathrm{HbA}_{1 \mathrm{c}}$ was preserved in multivariable analysis after adjusting for diabetes duration, sex, height and SBP (Table 2) and for DBP (model 2, data not shown). There was a sex difference for all four outcomes, with wider vessels (CRAE, CRVE, MWa and MWv) associated with girls in the multivariate analyses.

\section{Discussion}

This large cross-sectional study of adolescents with type 1 diabetes is the first to examine peripheral retinal zone vessels 
Table 1 Participant characteristics by $\mathrm{HbA}_{1 \mathrm{c}}$ tertile a
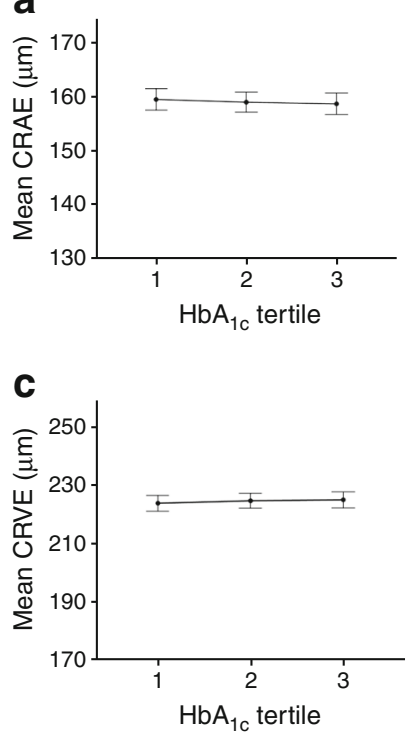

b
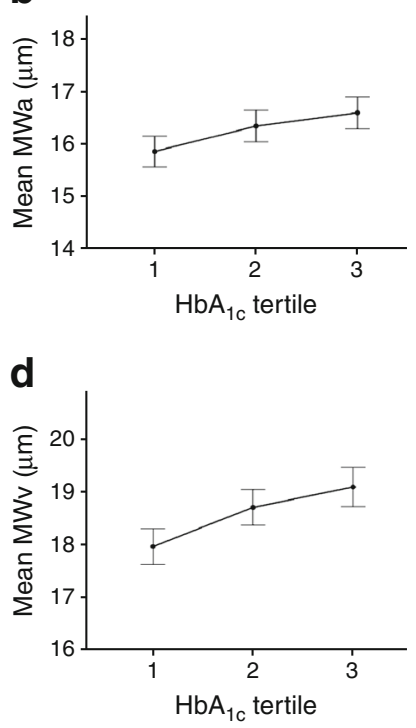

Fig. 2 Distribution of central and peripheral retinal vessel calibres by $\mathrm{HbA}_{1 \mathrm{c}}$ tertile. Graphs show the relationship of $\mathrm{HbA}_{1 \mathrm{c}}$ with (a) CRAE (in zone B), (b) MWa (in zone C), (c) CRVE (in zone B) and (d) MWv (in zone C) and their relationship with clinically important risk factors, in particular with glycaemia and BP. We demonstrate differential associations with SBP for central and peripheral retinal vessels, suggesting that peripheral retinal vessels respond adversely to poor glycaemic control earlier than central vessels. We also found that female sex was significantly associated with wider central and peripheral vessels.

Our novel finding that higher concurrent $\mathrm{HbA}_{1 \mathrm{c}}$ levels are associated with wider peripheral vessels is biologically plausible. It is well-established that the diabetic milieu results in relative systemic tissue hypoxia that can be visualised in the retina. We postulate that, to compensate for hyperglycaemiainduced retinal hypoxia, vasodilation ensues in an attempt to increase blood flow and tissue oxygenation.

The observed inverse association between higher BP and smaller central retinal vessels is in keeping with previous findings in older nondiabetic individuals [23-28]. In the Rotterdam Study, for example, a $10 \mathrm{mmHg}$ increase in SBP corresponded to a $1.1 \mu \mathrm{m}$ decrease in CRAE and $0.5 \mu \mathrm{m}$ decrease in CRVE; this was especially prominent in younger people [29]. Retinal circulation autoregulation aims to 
Table 2 Multivariable linear regression to explore associations between peripheral and central retinal vessel calibres and $\mathrm{HbA}_{1 \mathrm{c}}$, diabetes duration, sex, height and SBP

\begin{tabular}{|c|c|c|c|c|}
\hline & \multicolumn{2}{|l|}{ Univariate } & \multicolumn{2}{|l|}{ Multivariate } \\
\hline & $\beta(95 \% \mathrm{CI})$ & $p$ value & $\beta(95 \% \mathrm{CI})$ & $p$ value \\
\hline \multicolumn{5}{|l|}{ CRAE $(\mu \mathrm{m})$} \\
\hline $\mathrm{HbA}_{1 \mathrm{c}}(\mathrm{mmol} / \mathrm{mol})$ & $-0.04(-0.12,0.03)$ & 0.27 & - & - \\
\hline $\mathrm{HbA}_{1 \mathrm{c}}(\%)$ & $-0.43(-1.35,0.47)$ & 0.34 & - & - \\
\hline Duration of diabetes (years) & $0.70(0.36,1.04)$ & $<0.001$ & $0.93(0.58,1.28)$ & $<0.001$ \\
\hline $\operatorname{Sex}^{\mathrm{a}}$ & $-3.72(-5.84,1.59)$ & 0.001 & $-5.04(-7.26,-2.82)$ & $<0.001$ \\
\hline Height (cm) & $0.03(-0.08,0.14)$ & 0.60 & $0.20(0.08,0.32)$ & 0.002 \\
\hline $\mathrm{SBP}(\mathrm{mmHg})$ & $-0.25(-0.34,-0.17)$ & $<0.001$ & $-0.28(-0.37,-0.19)$ & $<0.001$ \\
\hline \multicolumn{5}{|l|}{ CRVE $(\mu \mathrm{m})$} \\
\hline $\mathrm{HbA}_{1 \mathrm{c}}(\mathrm{mmol} / \mathrm{mol})$ & $-0.02(-0.13,0.08)$ & 0.64 & - & - \\
\hline $\mathrm{HbA}_{1 \mathrm{c}}(\%)$ & $-0.30(-1.59,0.98)$ & 0.64 & - & - \\
\hline Duration of diabetes (years) & $0.79(0.30,1.27)$ & 0.001 & $0.91(0.42,1.41)$ & $<0.001$ \\
\hline $\operatorname{Sex}^{\mathrm{a}}$ & $-4.52(-7.54,-1.50)$ & 0.003 & $-5.83(-8.99,-2.68)$ & $<0.001$ \\
\hline Height $(\mathrm{cm})$ & $-0.02(-0.18,0.13)$ & 0.75 & $0.19(0.02,0.37)$ & 0.02 \\
\hline $\mathrm{SBP}(\mathrm{mmHg})$ & $-0.11(-0.24,0.009)$ & 0.06 & $-0.20(-0.33,-0.07)$ & 0.002 \\
\hline \multicolumn{5}{|l|}{ MWa $(\mu \mathrm{m})$} \\
\hline $\mathrm{HbA}_{1 \mathrm{c}}(\mathrm{mmol} / \mathrm{mol})$ & $0.01(0.007,0.03)$ & 0.002 & $0.01(0.004,0.03)$ & 0.007 \\
\hline $\mathrm{HbA}_{1 \mathrm{c}}(\%)$ & $0.21(0.07,0.34)$ & 0.002 & $0.19(0.05,0.33)$ & 0.006 \\
\hline Duration of diabetes (years) & $0.07(0.02,0.12)$ & 0.006 & $0.07(0.02,0.13)$ & 0.007 \\
\hline $\operatorname{Sex}^{\mathrm{a}}$ & $-0.44(-0.76,-0.13)$ & 0.006 & $-0.46(-0.81,-0.11)$ & 0.01 \\
\hline Height $(\mathrm{cm})$ & $-0.01(-0.02,0.005)$ & 0.17 & - & - \\
\hline $\mathrm{SBP}(\mathrm{mmHg})$ & $0.03(0.02,0.04)$ & $<0.001$ & $0.04(0.02,0.05)$ & $<0.001$ \\
\hline \multicolumn{5}{|l|}{ MWv $(\mu \mathrm{m})$} \\
\hline $\mathrm{HbA}_{1 \mathrm{c}}(\mathrm{mmol} / \mathrm{mol})$ & $0.02(0.01,0.04)$ & 0.001 & $0.02(0.009,0.03)$ & 0.001 \\
\hline $\mathrm{HbA}_{1 \mathrm{c}}(\%)$ & $0.27(0.12,0.43)$ & 0.001 & $0.22(0.06,0.38)$ & 0.005 \\
\hline Duration of diabetes (years) & $0.04(-0.01,0.10)$ & 0.16 & - & - \\
\hline $\operatorname{Sex}^{\mathrm{a}}$ & $-0.48(-0.85,-0.11)$ & 0.01 & $-0.46(-0.87,-0.06)$ & 0.02 \\
\hline Height (cm) & $-0.01(-0.03,0.002)$ & 0.08 & $-0.02(-0.04,-0.003)$ & 0.02 \\
\hline $\mathrm{SBP}(\mathrm{mmHg})$ & $0.04(0.03,0.06)$ & $<0.001$ & $0.04(0.03,0.06)$ & $<0.001$ \\
\hline
\end{tabular}

${ }^{\mathrm{a}}$ Female $=0 ;$ male $=1$

Only significant values are reported for the multivariate analyses optimise blood flow. Laser doppler velocimetry shows that hyperglycaemia causes increased blood flow, and that increases in BP result in further increased blood flow in diabetic but not in nondiabetic individuals [13]. With increased BP, we observed narrower central vessels and wider peripheral vessels, probably due to compensatory autoregulation in response to increased blood flow and BP [13].

We hypothesise that the observed vasodilation of the peripheral vessels may be an adaptive/maladaptive change in an attempt to improve tissue perfusion by decreasing vascular resistance further downstream. Such decreases in pressure in an already low pressure, low velocity system may result in stasis, further contributing to vascular damage.

The retinal arteries lose their internal elastic lamina soon after they bifurcate at the optic disc. As a compensatory mechanism the retinal arteries have a thicker muscularis layer, which allows vasoconstriction in response to pressure and/or chemical stimuli. With increasing distance from the optic disc, pericytes replace the smooth muscle cells in retinal veins. Pericytes interact with the surrounding endothelial cells providing vessel stability [30] and play a role in angiogenesis [31]. Post-mortem studies have shown early pericyte loss in people with diabetes, with a low pericyte to endothelial cell ratio of $1: 4$, compared with $1: 1$ in nondiabetic individuals [32]. Apoptosis of pericytes is the earliest retinal change noted in hyperglycaemia and eventually leads to retinal nonperfusion [19, 33]. Pericyte loss leads to further vasomotor dysregulation, loss of structural support, capillary dropout and sustained vasodilation in animal studies [34]. Furthermore, human studies have suggested that widening of retinal arterioles could increase the risk of incident retinopathy as a result of a breakdown in autoregulation $[4,15]$.

Dynamic vascular responses are impaired in diabetes [35]. Retinal blood flow in diabetes has been shown to be increased, 
especially early in the disease $[36,37]$. Retinal vasodilatation and hyperperfusion related to hypoxia and nitric oxide release are postulated to be key initiating factors in retinopathy development $[13,14]$. Hyperperfusion is associated with impaired autoregulation, increased shear stress and leads to the development of microaneurysms [15]. Retinal venular dilation may reflect endothelial dysfunction and increased production of nitric oxide secondary to higher levels of cytokines often associated with diabetes [38-41].

We postulate that the adverse effects of hyperglycaemia in smaller vessels precede vasodilatory changes in the larger vessels. This would account for the wider central venules (CRVE) with higher $\mathrm{HbA}_{1 \mathrm{c}}$ in individuals whose duration of diabetes was longer than in the current study (mean 15 years vs 5 years) [42].

Wider vessels are predictive of retinopathy and other microvascular complications in type 1 diabetes [4, 43]. In a prospective cohort study of young individuals with type 1 diabetes who were free of retinopathy at baseline, we previously demonstrated that (central) retinal arteriolar dilatation was associated with incident retinopathy [4], but unlike in the present study, the peripheral vessels were not analysed. Our present results, showing wider vessel calibres with longer diabetes duration, are consistent with previous studies showing progression of retinopathy in adults with type 1 diabetes with increasing diabetes duration [44]. While our study group did not have retinopathy, future longitudinal analyses should examine the predictive role of peripheral vessels on retinopathy. Our finding that girls had wider vessels may suggest that their future risk of microvascular complications is greater. Sexual dimorphism in diabetes complications has been previously described $[44,45]$. This is likely to be due to early pubertal growth spurt, hormonal changes in puberty, including vasodilatory effects of oestrogen and progesterone, and higher rates of insulin resistance in women [44, 45].

The retinal changes associated with BP in retinopathy-free normotensive individuals, such as our study population, are important and warrant closer monitoring. We found that higher SBP was associated with narrower central vessels but, in contrast, with wider peripheral vessels. Higher BP, albeit in the normal range, is important because it has a significant association with development of retinopathy in adolescents. Higher $\mathrm{BP}$ in itself accentuates shear stress and microvascular damage. In a prospective cohort study of adolescents with type 1 diabetes (median age 13.4 [IQR 12-15.2] years, duration of diabetes 4.9 [3.1-7] years), we have previously shown that higher SBP and DBP were predictors of retinopathy. The cumulative risk of retinopathy after 10 years of diabetes was higher for those with SBP and DBP on or above the 90th centile compared with those below the 90th centile [23]. Thus it seems likely that the narrowing of the central vessels precedes and contributes to increase BP in an attempt to improve perfusion in response to the relative neuroretinal ischaemia in the diabetic milieu in which a dynamic vicious cycle may exist in a maladaptive attempt to maintain the microcirculation [46].

Quantifying peripheral retinal vessels is non-invasive and can be applied to retinal photographs, which are commonly used in clinical practice. Early changes in smaller vessels may assist in elucidating mechanistic pathways that lead to microand macrovascular complications. Furthermore, smaller retinal vessels may be more sensitive to intervention making them potential biomarkers of disease progression and measures of response to therapy.

The strengths of this study include the large study population of individuals who are probably representative of young people with type 1 diabetes in Australia as most are cared for by endocrinologists in public hospital clinics, such as the site of this study. Potential limitations are the lack of nondiabetic control individuals and the cross-sectional study design that includes only concurrent $\mathrm{HbA}_{1 \mathrm{c}}$ and $\mathrm{BP}$ levels. We were not able to adjust for confounders of refraction or magnification but these factors are unlikely to affect peripheral and central vessels preferentially. Longitudinal studies with multiple measures of retinal status and systemic risk factors are warranted to confirm and extend our novel findings for the development of retinopathy.

In conclusion, our data shows that peripheral retinal vessels demonstrate changes before the central retinal vessels in retinopathy-free adolescents with type 1 diabetes. Higher $\mathrm{HbA}_{1 \mathrm{c}}$ was associated with wider peripheral vessels but not central retinal vessels. Assessment of peripheral retinal vessel calibres may provide insight into early microvascular changes associated with diabetes and its complications. Ultimately this non-invasive test, which can be derived from retinal photographs, may be valuable for clinical practice.

Acknowledgements The authors would like to thank J. Cusumano and A. Pryke from the Diabetes Complications Assessment Service, The Children's Hospital at Westmead, Australia, and the participants and their families who participated in this study.

Data availability The data are available on request from the authors.

Funding This research received no specific grant from any funding agency in the public, commercial or not-for-profit sectors.

Duality of interest The authors declare that there is no duality of interest associated with this manuscript.

Contribution statement AJ, TW, KD and PB devised the study design. $\mathrm{KD}, \mathrm{MC}$ and TW collected the data. VV analysed the data with PB and wrote the manuscript. GL was involved in the interpretation of the data and contributed to the discussion and editing of the manuscript. MC, AJ, $\mathrm{PB}, \mathrm{KD}$ and TW were involved in editing the manuscript. All the authors have approved the final version of the manuscript. As the corresponding author and guarantor of this article, KD takes full responsibility for the work as a whole, including the study design, access to data, and the decision to submit and publish the manuscript. 


\section{References}

1. Mohsin F, Craig ME, Cusumano J et al (2005) Discordant trends in microvascular complications in adolescents with type 1 diabetes from 1990 to 2002. Diabetes Care 28:1974-1980

2. Alder VA, Su EN, Yu DY, Cringle SJ, Yu PK (1997) Diabetic retinopathy: early functional changes. Clin Exp Pharmacol Physiol 24:785-788

3. Benitez-Aguirre P, Craig ME, Sasongko MB et al (2011) Retinal vascular geometry predicts incident retinopathy in young people with type 1 diabetes: a prospective cohort study from adolescence. Diabetes Care 34:1622-1627

4. Cheung N, Rogers SL, Donaghue KC, Jenkins AJ, Tikellis G, Wong TY (2008) Retinal arteriolar dilation predicts retinopathy in adolescents with type 1 diabetes. Diabetes Care 31:1842-1846

5. Cheung N, Sharrett AR, Klein R et al (2007) Aortic distensibility and retinal arteriolar narrowing: the multi-ethnic study of atherosclerosis. Hypertension 50:617-622

6. Dalla Pozza R, Beyerlein A, Thilmany C et al (2011) The effect of cardiovascular risk factors on the longitudinal evolution of the carotid intima medial thickness in children with type 1 diabetes mellitus. Cardiovasc Diabetol 10:53

7. Gopinath B, Chiha J, Plant AJ et al (2014) Associations between retinal microvascular structure and the severity and extent of coronary artery disease. Atherosclerosis 236:25-30

8. Liao D, Wong TY, Klein R, Jones D, Hubbard L, Sharrett AR (2004) Relationship between carotid artery stiffness and retinal arteriolar narrowing in healthy middle-aged persons. Stroke 35:837-842

9. Rogers SL, Tikellis G, Cheung N et al (2008) Retinal arteriolar caliber predicts incident retinopathy: the Australian Diabetes, Obesity and Lifestyle (AusDiab) study. Diabetes Care 31:761-763

10. Klein R, Klein BE, Moss SE, Wong TY (2007) Retinal vessel caliber and microvascular and macrovascular disease in type 2 diabetes: XXI: the Wisconsin epidemiologic study of diabetic retinopathy. Ophthalmology 114:1884-1892

11. Cogan DG, Toussaint D, Kuwabara T (1961) Retinal vascular patterns. IV. Diabetic retinopathy. Arch Ophthalmol 66:366-378

12. Kuwabara T, Cogan DG (1963) Retinal vascular patterns. VI. Mural cells of the retinal capillaries. Arch Ophthalmol 69:492-502

13. Kohner EM, Patel V, Rassam SM (1995) Role of blood flow and impaired autoregulation in the pathogenesis of diabetic retinopathy. Diabetes 44:603-607

14. Scherrer U, Randin D, Vollenweider P, Vollenweider L, Nicod P (1994) Nitric oxide release accounts for insulin's vascular effects in humans. J Clin Invest 94:2511-2515

15. Gardiner TA, Archer DB, Curtis TM, Stitt AW (2007) Arteriolar involvement in the microvascular lesions of diabetic retinopathy: implications for pathogenesis. Microcirculation 14:25-38

16. Schram MT, Chaturvedi N, Schalkwijk CG, Fuller JH, Stehouwer CD, Group EPCS (2005) Markers of inflammation are crosssectionally associated with microvascular complications and cardiovascular disease in type 1 diabetes-the EURODIAB Prospective Complications Study. Diabetologia 48:370-378

17. McGahon MK, Dash DP, Arora A et al (2007) Diabetes downregulates large-conductance $\mathrm{Ca} 2+-$ activated potassium beta 1 channel subunit in retinal arteriolar smooth muscle. Circ Res 100:703-711

18. Wong TY, Klein R, Klein BE, Meuer SM, Hubbard LD (2003) Retinal vessel diameters and their associations with age and blood pressure. Invest Ophthalmol Vis Sci 44:4644-4650

19. Ejaz S, Chekarova I, Ejaz A, Sohail A, Lim CW (2008) Importance of pericytes and mechanisms of pericyte loss during diabetes retinopathy. Diabetes Obes Metab 10:53-63

20. Virk SA, Donaghue KC, Cho YH et al (2016) Association between $\mathrm{HbA}_{1 \mathrm{c}}$ variability and risk of microvascular complications in adolescents with type 1 diabetes. J Clin Endocrinol Metab 101: 3257-3263

21. Knudtson MD, Lee KE, Hubbard LD, Wong TY, Klein R, Klein BE (2003) Revised formulas for summarizing retinal vessel diameters. Curr Eye Res 27:143-149

22. (2014) National high blood pressure education program working group on high blood pressure in children and adolescents. The fourth report on the diagnosis, evaluation, and treatment of high blood pressure in children and adolescents. Pediatrics 114(Suppl 2):555-576

23. Gallego PH, Craig ME, Hing S, Donaghue KC (2008) Role of blood pressure in development of early retinopathy in adolescents with type 1 diabetes: prospective cohort study. BMJ 337:a918

24. Ikram MK, Witteman JC, Vingerling JR, Breteler MM, Hofman A, de Jong PT (2006) Retinal vessel diameters and risk of hypertension: the Rotterdam study. Hypertension 47:189-194

25. Kawasaki R, Cheung N, Wang JJ et al (2009) Retinal vessel diameters and risk of hypertension: the multiethnic study of atherosclerosis. J Hypertens 27:2386-2393

26. Smith W, Wang JJ, Wong TY et al (2004) Retinal arteriolar narrowing is associated with 5-year incident severe hypertension: the Blue Mountains Eye Study. Hypertension 44:442-447

27. Wong TY, Klein R, Sharrett AR et al (2004) Retinal arteriolar diameter and risk for hypertension. Ann Intern Med 140:248-255

28. Wong TY, Shankar A, Klein R, Klein BE, Hubbard LD (2004) Prospective cohort study of retinal vessel diameters and risk of hypertension. BMJ 329:79

29. Ikram MK, de Jong FJ, Vingerling JR et al (2004) Are retinal arteriolar or venular diameters associated with markers for cardiovascular disorders? The Rotterdam study. Invest Ophthalmol Vis Sci 45:2129-2134

30. von Tell D, Armulik A, Betsholtz C (2006) Pericytes and vascular stability. Exp Cell Res 312:623-629

31. Gerhardt H, Betsholtz C (2003) Endothelial-pericyte interactions in angiogenesis. Cell Tissue Res 314:15-23

32. Speiser P, Gittelsohn AM, Patz A (1968) Studies on diabetic retinopathy. 3. Influence of diabetes on intramural pericytes. Arch Ophthalmol 80:332-337

33. Wilkinson-Berka JL (2004) Diabetes and retinal vascular disorders: role of the renin-angiotensin system. Expert Rev Mol Med 6:1-18

34. Curtis TM, Gardiner TA, Stitt AW (2009) Microvascular lesions of diabetic retinopathy: clues towards understanding pathogenesis? Eye 23:1496-1508

35. Lim LS, Ling LH, Ong PG et al (2014) Dynamic responses in retinal vessel caliber with flicker light stimulation in eyes with diabetic retinopathy. Invest Ophthalmol Vis Sci 55:5207-5213

36. Grunwald JE, DuPont J, Riva CE (1996) Retinal haemodynamics in patients with early diabetes mellitus. Br J Ophthalmol 80:327-331

37. Pemp B, Polska E, Garhofer G, Bayerle-Eder M, Kautzky-Willer A, Schmetterer L (2010) Retinal blood flow in type 1 diabetic patients with no or mild diabetic retinopathy during euglycemic clamp. Diabetes Care 33:2038-2042

38. Chester AH, Borland JA, Buttery LD et al (1998) Induction of nitric oxide synthase in human vascular smooth muscle: interactions between proinflammatory cytokines. Cardiovasc Res 38:814-821

39. de Rekeneire N, Peila R, Ding J et al (2006) Diabetes, hyperglycemia, and inflammation in older individuals: the health, aging and body composition study. Diabetes Care 29:1902-1908

40. Jeganathan VS, Sabanayagam C, Tai ES et al (2009) Retinal vascular caliber and diabetes in a multiethnic Asian population. Microcirculation 16:534-543

41. Wilkinson-Berka JL (2004) Vasoactive factors and diabetic retinopathy: vascular endothelial growth factor, cycoloxygenase- 2 and nitric oxide. Curr Pharm Des 10:3331-3348

42. Klein R, Klein BE, Moss SE et al (2003) Retinal vascular abnormalities in persons with type 1 diabetes: the Wisconsin 
Epidemiologic Study of Diabetic Retinopathy: XVIII. Ophthalmology 110:2118-2125

43. Wong TY, Shankar A, Klein R, Klein BE (2004) Retinal vessel diameters and the incidence of gross proteinuria and renal insufficiency in people with type 1 diabetes. Diabetes 53:179-184

44. Monti MC, Lonsdale JT, Montomoli C, Montross R, Schlag E, Greenberg DA (2007) Familial risk factors for microvascular complications and differential male-female risk in a large cohort of
American families with type 1 diabetes. J Clin Endocrinol Metab 92:4650-4655

45. Benitez-Aguirre P, Craig ME, Cass HG et al (2015) Sex differences in retinal microvasculature through puberty in type 1 diabetes: are girls at greater risk of diabetic microvascular complications? Invest Ophthalmol Vis Sci 56:571-577

46. Ding J, Wai KL, McGeechan K et al (2014) Retinal vascular caliber and the development of hypertension: a meta-analysis of individual participant data. J Hypertens 32:207-215 